\title{
"Apaixonados por carros como todo brasileiro" (?) - Reflexões frankfurteanas sobre a indústria cultural contemporânea
}

\section{“Passionate by cars like all Brazilians" (?) - Frankfurt School's reflections about the contemporary culture industry}

\author{
Rebeca Carvalho de Morais* \\ Universidade Federal do Ceará - UFC, Fortaleza, Ceará, Brasil \\ Jesus Garcia Pascual** \\ Universidade Federal do Ceará - UFC, Fortaleza, Ceará, Brasil \\ Maria de Fátima Vieira Severiano*** \\ Universidade Federal do Ceará - UFC, Fortaleza, Ceará, Brasil
}

\begin{abstract}
RESUMO
O presente artigo tem por objetivo tecer uma reflexão crítica acerca da "paixão" enunciada pela campanha de marketing da empresa de combustíveis Ipiranga, a partir das contribuições teóricas formuladas por Adorno e Horkheimer, teóricos da Escola de Frankfurt, no que concerne ao conceito de Indústria Cultural. Salientamos, desde já, que este ensaio não visa a estudar epistemologicamente a referida Escola, mas sim a apontar a atualidade do conceito de "indústria cultural". Em vista da atual crença na felicidade a partir do consumo idealizado de mercadorias, disseminados pela publicidade, o presente trabalho tem por objetivo tecer uma reflexão crítica acerca da Indústria Cultural contemporânea e suas implicações psicossociais na atual constituição das subjetividades, a partir da Teoria Crítica. Tomamos como exemplar da referida Indústria o slogan publicitário: "Apaixonados por carro como todo brasileiro", que divulga como "cultura de massa" esta "paixão". Metodologicamente procedemos a uma revisão de conceitos da Escola de Frankfurt vinculados à racionalidade técnico-instrumental moderna, apontando a atualidade do conceito de "indústria cultural" e diferenciando-o de uma cultura originária das massas. A pesquisa empírica, cuja estratégia metodológica consistiu em recolhermos depoimentos de internautas em 12 sites relacionados à temática do slogan, visou investigar as atuais formas de adesão/resistência ao referido slogan. Em nossa leitura teórico-crítica dos depoimentos, apesar das formas de adesão fascinadas serem majoritárias, também detectamos formas de resistência; o que nos aponta que esta "paixão", como muitas outras proclamadas pela indústria cultural, não emerge espontaneamente dos brasileiros, mas que, em verdade, foi construída para os brasileiros - forma atualizada do fetichismo da mercadoria.
\end{abstract}

Palavras-chave: Indústria cultural; Subjetividades contemporâneas; Publicidade; Carro; Consumo. 


\begin{abstract}
The objective of this article is to make a critical reflection about the "passion" enunciated by the Ipiranga's marketing campaign, using the theoretical contributions made by Adorno and Horkheimer, theorists of the Frankfurt School, related to the concept of "culture industry". We emphasize that this essay is not intended to explore the Frankfurt School's epistemology, but to point out the topicality of the concept "culture industry". Given the current belief, disseminated by the Publicity, that happiness can be reached by the consumption of objects, our intention is to critically reflect about the current "culture industry" and its psychosocial implications in the formation of contemporary subjectivities. We take as an example of that industry the following slogan: "Passionate by cars like all Brazilians" that discloses that "passion" as "mass culture". Methodologically, we 've made a review of the Frankfurt School's concepts linked to technicalinstrumental modern rationality, pointing the topicality of the "culture industry" concept, differentiating it from a culture derived from the mass. The empirical research, whose methodological strategy was to collect testimonies of internet's users in 12 (twelve) sites related with the slogan above mentioned, aimed to explore the forms of adhesion / resistance to that slogan. In our theoretical-critical reading of the testimonials, despite of the fascinated adhesions are the majority, we also detected forms of resistance; which shows us that this "passion", such as many others proclaimed by the "culture industry", did not emerged spontaneously from Brazilians, but, in fact, it was built for Brazilians - updated form of the object's fetish zed form.
\end{abstract}

Keywords: Culture industry; Contemporary subjectivities; Publicity; Car; Consumption.

\title{
1 Introdução
}

Apaixonado por carro (música)

Carro de apaixonado tem que ter um som; pra chegar no calçadão e abrir o som. Tomar uma geladinha escutando o som; carro de apaixonado não pode ficar sem som. Carro de apaixonado tem que ter um som; pra chegar no calçadão e abrir o som. Tomar uma geladinha escutando o som; carro de apaixonado não pode ficar sem som. Eu tomei uma cerveja e abri o som; toda a galera parou pra ouvir o meu som. A turma do calçadão se ligou no som; carro de apaixonado não pode ficar sem som. Passou o cara gritando quer vender o som? A polícia foi chegando mandou desligar o som. Todo calçadão estava ligado no som; carro de apaixonado não pode ficar sem som. (Música da 'Companhia Calypso')

A música epígrafe deste artigo exemplifica, de forma significativa, o sentimento - paixão - que, segundo a mídia contemporânea, parece afetar a maioria dos brasileiros quando o assunto é "carro". Esta dita "paixão" também foi alvo de uma campanha publicitária da empresa de combustíveis "Ipiranga", cujo slogan é: "Apaixonados por carro como todo brasileiro". ${ }^{1}$ 
Considerando-se que vivemos sob a égide de uma "Sociedade do Consumo" (BAUDRILLARD, 1970), cuja preocupação acentuada com a realização individual privada está em estreita ligação com as opções do consumidor, a nossa inquietação inicial diz respeito ao questionamento acerca da veracidade desta afirmação. Neste sentido, o presente artigo tem por objetivo tecer uma reflexão crítica acerca da "paixão" enunciada pela citada campanha de marketing, a partir das contribuições teóricas formuladas por Adorno e Horkheimer, teóricos da Escola de Frankfurt, no que concerne ao conceito de Indústria Cultural. Salientamos, desde já, que este ensaio não visa a estudar epistemologicamente a referida Escola, mas sim a apontar a atualidade do conceito de "indústria cultural", cunhado por Adorno e Horkheimer em 1947.

Nossa hipótese inicial é a de que o slogan "Apaixonados por carro como todo brasileiro" não expressaria um sentimento emanado espontaneamente da população brasileira - "cultura de massas"-, mas estaríamos diante de uma estratégia mercadológica - "indústria cultural" -, cujo intuito seria o aumento das vendas de carros.

O recurso teórico-metodológico utilizado é o da "crítica imanente", na qual "o particular, longe de ser dado como irrelevante, é a via através da qual a crítica, verrumando por dentro do seu objeto, consegue aceder ao todo" (ROUANET, 1983, p. 104); ou seja, através da análise de um elemento particular da atual cultura de consumo - um slogan publicitário -, objetivamos expressar elementos representativos das formas de subjetivação contemporâneas. Esta abordagem se caracteriza, portanto, por um desvelamento dos "bastidores" dos acontecimentos para que seja possível descobrir, através de uma razão reflexiva, os percalços que formaram e/ou mantêm um determinado status quo, examinando o objeto em suas múltiplas determinações. Não se trata, assim, de delinear correlações topológicas ${ }^{2}$, mas de considerar que este objeto pode funcionar como índice de uma particularidade concreta que contém em si, partes do universal, pois como já afirmaram Adorno e Horkheimer (1985): "O todo e o detalhe exibem os mesmos traços [...]" (p. 104).

Como fonte de dados, utilizamos a internet, cuja escolha se deve ao grande destaque que as novas tecnologias ocupam no cenário contemporâneo. Os dispositivos digitais (computador, telefone celular, TV digital) tornam-se "portais" de socialização - generalista, temático, empresarial, pessoal - cada vez mais difundidos, tendo inclusive a inclusão digital tornado-se tema de pesquisas em teses de doutoramento (BUZATO, 2008). Também é possível encontrar estudos que apontam a socialização midiática como um componente de um novo tipo de inteligência, a "inteligência coletiva" (LEVY, 2000) ou outros que buscam compreender os desafios entre "internet e ensino" (ARAÚJO, 2007). 
Percorrendo portais de internet, optamos pelo Google por se tratar de um portal generalista, tal como o Yahoo, mas que, segundo Santos (apud ARAÚJO, 2007, p. 277), é o mais usual do tipo comercial. Mediante o referido portal, procuramos depoimentos de internautas acerca do slogan da Ipiranga, buscando perceber sua influência na constituição das opiniões dos brasileiros sobre o tema carro, bem como procurando desvelar uma possível influência midiática ${ }^{3}$ na formação desta "paixão", o que a caracterizaria como um processo mercadologicamente construído - "indústria cultural". Recolhemos depoimentos de pessoas em 12 (doze) sites ${ }^{4}$ relacionados ao assunto nos dias 26/09/2009 e 30/09/2009 e, posteriormente, analisamos os conteúdos a partir do eixo teórico-metodológico da Teoria Crítica.

Acreditamos que este tema possui relevância para nossa área de pesquisa na medida em que a publicidade se constitui em um núcleo privilegiado da produção simbólica contemporânea, a partir da qual se produzem modelos de conduta e novas formas de subjetividade. Por meio dela, o consumidor é constantemente mobilizado em seus desejos, através de imagens publicitárias que associam objetos e serviços a atributos subjetivos e psicossociais idealizados. Para a consecução de tais propósitos, os media utilizam mecanismos "nada espontâneos" que, segundo Mezan (2002), possuem uma dupla função: "suscitar impulsos ali onde não existiam e persuadir o indivíduo a satisfazê-los adquirindo o objeto ou serviço anunciado" (p. 303).

Nesse processo, transmuta-se o valor de uso das mercadorias em valor simbólico, no qual "os símbolos assumem a expressão do fetiche" (ADORNO; HORKHEIMER, 2000, p. 38). Desse modo, o fetichismo da mercadoria (MARX, 1984) ocultaria na atualidade, não só as relações sociais de trabalho, mas receberia um duplo reforço: ao objeto passam a se incorporar poderes imateriais e simbólicos alienantes da própria subjetividade humana, na medida em que encarnam ideais subjetivos de segurança, diferenciação, autonomia, felicidade etc., como se estes emanassem da própria mercadoria; alijando, desta forma, o indivíduo da compreensão dos determinantes psicossociais e históricos presentes no processo de produção e de consumo (SEVERIANO, 2007).

Nesta perspectiva, vale relembrar que para Adorno (1978) tornar absoluta a cisão entre indivíduo e sociedade é falsa consciência na medida em que eterniza uma realidade histórica mantida socialmente pela reprodução do que ele denomina de sociedade individualista. Sendo assim, inserimos este estudo na perspectiva da Psicologia Social Crítica que se interroga sobre o campo social mediante uma compreensão da relação entre indivíduo e sociedade não como algo dissociado entre si, tampouco, como uma totalidade homogênea e pacificadora, mas como um campo de tensão, objetivando 
[...] buscar nas relações entre indivíduo e sociedade as rupturas e as continuidades, suas transformações mútuas e as permanências, os pontos de possível semelhança de interesses e reconciliação, mas não anulação, e os momentos de resistência de um para com o outro (RAMOS, 2004, p. 24).

Salientamos, ainda, que compreendemos a subjetividade como um processo que se desenvolve a partir da interiorização da cultura sem, entretanto, se reduzir a ela; é por isso que o "[...] sujeito, ao qual é associado o termo subjetividade, remete, simultaneamente, à universalidade e à particularidade" (CROCHIK, 1998). Nesta mesma perspectiva, concordamos com Ewald e Soares (2007), segundo os quais, a subjetividade seria o primeiro nome moderno da identidade, estando relacionada àquilo que "pertence à consciência individual, como também pertence ao pensamento humano" (EWALD; SOARES, 2007 , p. 24). Desta forma, a singularidade humana se definiria a partir da inter-relação entre a "identidade cultural" e a "identidade pessoal". A primeira pode ser designada como uma unidade expressiva de valores, crenças e significados que orientam a ação de uma comunidade e que acabam por influenciar, de forma fundamental, a formação da "identidade pessoal", ou seja, a formação da "singularidade, o si mesmo" (EWALD; SOARES, 2007, p. 24). A identidade humana se constituiria, portanto, no momento de interseção, ou seja, através da relação entre o cultural e o pessoal. É neste sentido que os referidos autores afirmam:

[...] ao nos referirmos à identidade, falamos de zonas de interseções, de vários tipos e tamanhos, pois são zonas de compartilhamento intersubjetivo com um grupo, um time de futebol, um bairro, uma cidade, um estado, um país, uma opção ideológica-política, etc., mas onde, também sempre haverá o espaço da singularidade (EWALD; SOARES, 2007, p. 24).

Desta forma, considerando que as subjetividades constituem-se na inter-relação entre os fatores intrapsíquicos e os aspectos psicossociais, faz-se relevante tecer algumas ponderações críticas acerca das atuais formas de subjetivação engendradas pela indústria cultural; sob a suspeita que esta tende a potencializar processos de fetichização do objeto, produzindo um possível esvaziamento do pensamento crítico-reflexivo e uma concomitante exacerbação dos sentimentos de insuficiência humana. Nela se produziria "sujeitos incompletos" (falta o carro que não possui; falta a viagem que não realizou; falta o estrelato que não tem; falta o corpo ideal), obedientes (compra de produtos que foram fabricados "especialmente" para sua a felicidade) e frustrados (inacessibilidade aos perfis ideais, o que leva a constantes fracassos por parte dos 
indivíduos e ao surgimento dos "novos transtornos": anorexias, bulimias, depressões, compulsões etc.). ${ }^{5}$

Transmuta-se, assim, o social em natural; e, desse modo, desejos subjetivos socialmente fabricados seriam difundidos como naturais, corroborando o que Adorno e Horkheimer (1985) já afirmaram: "O paradoxo da rotina travestida de natureza pode ser notado em todas as manifestações da indústria cultural" (p. 106). Desta forma, o ser e o ter equacionam-se nos balcões das revendedoras de automóveis e combustíveis.

Neste sentido, nossa pesquisa busca contribuir para a elucidação de estratégias publicitárias, cuja promessa de preencher insidiosamente a "falta subjetiva" que ela mesma cria, finda por promover exaustivamente seus bens de consumo, como solução para a incompletude humana, agregando valores heterônomos, como se estes emanassem originalmente dos próprios consumidores.

Como asseveraram Adorno e Horkheimer (1985, p. 100):

A atitude do público que, pretensamente e de fato, favorece o sistema da indústria cultural é uma parte do sistema, não sua desculpa [...] o recurso aos desejos espontâneos do público torna-se uma desculpa esfarrapada [...] o que o explica é o círculo da manipulação e da necessidade retroativa, no qual a unidade do sistema se torna cada vez mais coesa.

\section{O cenário da Escola de Frankfurt - revisitando a dialética do Iluminismo}

A Escola de Frankfurt é a referência-base para o presente estudo. Formada por um grupo de pesquisadores que objetivaram revisar o projeto da Modernidade, estes teóricos procuraram compreender a "relação entre a vida econômica da sociedade, o desenvolvimento psíquico dos indivíduos e as possíveis e inevitáveis mudanças culturais que daí adviriam" (SOARES, 2007, p. 485), ou seja, buscaram analisar a interação entre os elementos culturais e psíquicos dos indivíduos que formavam a sociedade.

A denominação "Escola de Frankfurt" refere-se simultaneamente a um grupo de intelectuais e a uma teoria social, embora Freitag (2004, p. 33) alerte que "o termo Escola de Frankfurt ou a concepção de uma teoria crítica sugerem uma unidade temática e um consenso epistemológico, teórico e político que raras vezes existiu entre os representantes da Escola". Nem o nome denota fidelidade topológica nem a teoria denota unicidade. Tal afirmação da autora germanobrasileira sustenta-se (em relação ao local) porque uma parte dos escritos desses autores fora realizada fora de Frankfurt e não há necessariamente (em relação à teoria) unidade de pensamento entre 
os membros, chegando estes inclusive a discordarem em algumas teorizações. O que perpassa, contudo, as elaborações teóricas da Escola Frankfurt são:

[...] capacidade intelectual e crítica, reflexão dialética, competência dialógica ou aquilo que Habermas viria a chamar de "discurso", ou seja, o questionamento radical dos pressupostos de cada posição e teorização adotada (FREITAG, 2004, p. 33).

Pode-se afirmar que tais autores são unidos menos por uma teoria e mais por uma perspectiva que rejeita a realidade dada como a única possível, exercitando a "dialética negativa" de pensar o ainda não pensado como crítica, como uma possibilidade alternativa de futuro (SOARES, 2007, p. 474).

Os temas que perpassam o cenário da Escola de Frankfurt são três: razão, cultura e Estado. Embora seja apenas o segundo tema o objeto de estudo deste trabalho, torna-se relevante para uma apreensão mais adequada das formulações que perpassam o conceito de indústria cultural, apresentarmos resumidamente as derivações que a dialética da razão iluminista deposita sobre o tema da cultura.

Em relação à razão, esta se contorce entre o clarão ufanista das luzes (iluminista) e a constatação prática da sociedade (crítica), isto porque "o esclarecimento tem perseguido sempre o objetivo de livrar os homens do medo e investi-los na posição de senhores. Mas a terra totalmente esclarecida resplandece sob o signo de uma calamidade triunfal", advertem Horkheimer e Adorno (1985, p. 17). Refletindo sobre a deturpação dialética da razão iluminista, os autores mostram que a verdade não está escrita diretamente sobre a natureza, mas revestida pela interpretação social. Desse modo, Horkheimer e Adorno contrastam a teoria positivista - regida pelo binômio causa/consequência metodologicamente verificado, sem reflexão sobre a prática - com a teoria crítica. Esta, tendo como objetivo a dialética dos fatos, busca verificar vários ângulos de determinada questão a fim de desmistificar falsas verdades.

A partir de uma compreensão frankfurteana, o termo "crítica" expressa "negação" no sentido de recusar o estado das coisas como sendo um dado objetivo, sem uma contextualização histórica e/ou uma reflexão dialética. Desta forma, segundo Cohn (1998), crítica significa

[...] tomar aquilo de que se trata (que exatamente não é mero "objeto", coisa posta) como processo, como tendências que apontam tanto para suas possibilidades quanto para seus limites, e buscar pensar essas possibilidades e limites até o fim (COHN, 1998, p. 16). 
A necessidade de uma teoria crítica do social surgiu a partir do repúdio dos frankfurteanos ao conceito "sujeito" elaborado no Iluminismo alemão. No que tange ao kantismo o repúdio centra-se na identificação de sujeito e razão, esta considerada como faculdade a priori, isto é, aquela forma de conhecimento que dispensa a experiência sensível como fonte do verdadeiro conhecimento. Kant demonstra que: "O sujeito do conhecimento não é $[\ldots]$ o sujeito psicológico individual, mas uma estrutura universal, idêntica para todos os seres humanos em todos os tempos e lugares" (CHAUÍ, 1995 , p. 235). Desse modo, o sujeito transcendental kantiano nada mais é do que Razão como faculdade a priori do conhecer. Adorno e Horkheimer contrapõem-se, também, à concepção de "sujeito coletivo da história" elaborada por Hegel na medida em que ele é o "sujeito pleno" formado pelos indivíduos incompletos concretos. Ora, "o todo é o não- verdadeiro" (ADORNO apud OLIVEIRA, 1993, p. 79). A teoria crítica volta sua análise, num segundo momento, para a transmutação da dimensão iluminista da razão (no sentido transcendental kantiano) em "razão instrumental". Gerar uma teoria, prenhe de criticidade em relação à razão iluminista e à razão instrumental, eis a questão básica, fundamental, de onde partiu toda a Escola de Frankfurt, e de uma maneira muito especial, Adorno (OLIVEIRA, 1993).

Em suas críticas à razão iluminista, Adorno e Horkheimer (1985) expõem a face coercitiva do "esclarecimento". Para eles, o homem, em sua tentativa de domínio absoluto sobre a natureza, termina por desenvolver um domínio totalitário sobre si próprio e sobre os demais.

No primeiro caso, o homem pratica um ato de violência contra si, uma vez que a sua natureza submetida não resulta conciliada ou transcendida, mas sim reprimida. A repressão do impulso utópico e a destruição do desejo tornam o homem prisioneiro da realidade imediata, além de não eliminar o medo - razão pela qual o esclarecimento originalmente se desenvolveu. A razão, ao pretender conciliar-se com a realidade, à custa da repressão da natureza interna humana, termina por degradar-se a si mesma e transformarse no que estes autores denominaram de "razão instrumental": uma razão encurtada, formalizada e fatídica - mera justificação mistificadora do imediato.

Quanto à dominação em relação aos outros homens, a técnica constitui-se em sua maior expressão. Reside, justamente, na técnica a essência deste saber instrumental, que ao promover a dimensão da calculabilidade e da utilidade como fim último, rompe definitivamente o vínculo entre razão e interesse, passando a substituir o conceito pela fórmula, a causa pela regra e pela probabilidade; eliminando o sentido e a diferença para servir unicamente aos fins da tecnologia material. É o método que perde o seu estatuto de meio para tornar- 
se um fim em si. Como consequência, este suposto caráter "neutro" que a racionalidade adota leva a um profundo distanciamento dos homens entre si e com relação aos problemas centrais da humanidade: ética, justiça, liberdade, felicidade, etc., acerca dos quais ela não mais se pronuncia. Qualquer sistema político pode ser válido, contanto que seja eficaz.

As tentativas libertadoras modernas pareciam estar se esvaindo entre a tecnoburocracia do marxismo estalinizado e a crítica nietzshiana da razão. Por um lado, os ideais do Iluminismo, transcritos no lema kantiano "sapere aude!", pareciam esmorecer, retardando, desse modo, a emancipação humana nos alvores da Modernidade. Tal pensamento se sustenta na medida em que a estatização estalinista da sociedade anulava a força emancipatória da razão e obscurecia o Esclarecimento (Aufklärung). A hegemonia emancipatória da razão iluminista, por outro lado, era derrubada pela crítica que Nietzsche a fazia, pois "essa crítica é tão total que acaba sendo suicida, arrastando na ruína da razão a própria razão que realiza a crítica" (ROUANET, 1987, p. 96).

Desta forma, não é possível afirmar que a promessa iluminista de libertar os homens dos mitos por meio do uso razão foi cumprida. Pode-se reconhecer que ocorreram progressos tecnológicos e científicos, porém não é possível assegurar o mesmo em relação à emancipação humana e social, na medida em que os seres humanos tornaram-se capturáveis e escravos de uma racionalidade técnica, que visa meramente ajustar os meios a fins utilitaristas e instrumentais desvinculados de ações promotoras de autonomia e emancipação humana. ${ }^{6}$

Assim, tendo como base esta perspectiva crítica acerca da "razão iluminista", os frankfurteanos desenvolveram inúmeras reflexões acerca da época histórica na qual viviam. Dentre elas, destacamos para o presente artigo o conceito de indústria cultural, proposto por Adorno e Horkheimer em 1947 através da obra Dialética do Esclarecimento, escrita enquanto estes autores estavam exilados nos Estados Unidos. O contato com a cultura americana confrontou estes intelectuais com novos fenômenos que puseram em xeque conceitos como "entretenimento" e "cultura de massa"; o que propiciou o surgimento de uma crítica acerca dos novos mecanismos capitalistas de dominação e a percepção de que no mercado "tudo se transforma em artigo de consumo" (MATOS, 2005, p. 62), o que inclui a cultura e as subjetividades humanas.

\section{O cenário da Escola de Frankfurt - revisitando a teoria da indústria cultural}


O tema da cultura é abordado pelos frankfurteanos- Marcuse, Adorno e Horkheimer- a partir da distinção entre cultura e civilização. A sociedade burguesa emerge na Modernidade divorciando-se da classe trabalhadora com quem tinha pactuado aliança para derrubar a aristocracia. O modelo produtivo capitalista adotado pela burguesia cindiu a sociedade moderna em dois mundos contraditórios: os donos do produto (acumulando riqueza na mercadoria) e os trabalhadores do produto (acumulando desejo na mercadoria), pois o modelo capitalista distanciava cada vez mais o "capital" do "trabalho", enriquecendo os proprietários dos meios de produção e empobrecendo os operários, que recebiam salários apenas para manter a força para o trabalho.

Revendo as teses marxistas em sua crítica ao Capitalismo, a Escola de Frankfurt encontra modelos alternativos que a sociedade teria descoberto para sair da crise social no início do século XX. Os frankfurteanos colocam que nesta época houve uma separação entre cultura - mundo das ideias e dos sentimentos elevados -, que engloba os campos do ócio, os meios de comunicação de massa, a sexualidade, o cotidiano, etc., e a civilização - mundo da reprodução material. Segundo Freitag (2004), o mundo do trabalho (civilização) seria regido pela lógica da matéria, da necessidade, acabando por impor sofrimentos e abstenção aos seres humanos; já a esfera cultural permitia almejar liberdade, felicidade e realização espiritual, se não efetivadas no presente, ao menos prometidas para o futuro.

Foi a cisão entre as noções de civilização e cultura o que embasou a exploração e a alienação da maioria dos trabalhadores que sofriam nas linhas de produção e montagem das indústrias, pois os bens culturais possuíam o papel de acenar para um mundo melhor, no qual poderiam se concretizar os anseios por felicidade, liberdade, amor e humanidade (FREITAG, 2004, p. 69). Assim, este "aceno" foi a contribuição necessária para a conformação dos trabalhadores à administração burocrática e à vida miserável que tinham de suportar:

A ênfase dada à dimensão subjetiva, à interioridade dos sentimentos, aos valores espirituais, à dignidade da pobreza, etc., constituía uma forma de seduzir os membros da sociedade para se contentarem com promessas ou expectativas de felicidade no mundo espiritual, sem reivindicá-las ou estendê-las também às suas condições materiais de vida (FREITAG, 2004, p. 68).

Vale salientar que, tanto o acesso aos bens culturais quanto o acesso às condições materiais favoráveis, somente estava disponível para uma pequena parcela da população. As obras de arte, por exemplo, eram para o usufruto da burguesia sendo, em geral, vedadas aos trabalhadores; no entanto, ainda assim, conservavam a representação de um ideal não realizado denunciando, ao mesmo 
tempo, sua natureza irreconciliável com o princípio da realidade e preservando as esperanças e utopias do homem.

Porém, com o passar do tempo, "esse modelo foi se tornando segundo a análise de Marcuse - cada vez mais frágil e incapaz de contribuir para a manutenção do sistema de reprodução material, sobretudo na fase de ascensão da burguesia" (FREITAG, 2004, p. 70), o que exigiu do Estado e das empresas formas de intervenção mais eficazes para manter os trabalhadores inseridos no processo produtivo.

\begin{abstract}
A fim de tornar os trabalhadores dóceis e submissos, não bastava recorrer à dicotomia entre civilização e cultura, entre escassez material externa e riqueza espiritual interna. Tornou-se imperioso mudar os padrões de organização da produção cultural que foi sendo gradativamente cooptada pela esfera da civilização, isto é, sendo absorvida pelo sistema da produção de bens materiais que reestruturou inteiramente as formas de circulação e consumo da cultura (FREITAG, 2004, p. 70).
\end{abstract}

De tal modo, o que ocorreu é que os bens culturais, tais como obras literárias, sistemas filosóficos, obras de arte, dentre outros; foram "derrubados dos seus pedestais" (FREITAG, 2004, p. 71), ou seja, deixaram de ser bens de consumo de luxo destinados à burguesia, passando a bens de consumo de massa. Tal processo foi viabilizado graças à revolução tecnológico-industrial, que possibilitou a reprodução em série das obras de arte, contribuindo para que estas se transformassem em mercadorias. Ora, a transformação da arte em mercadoria finda por subverter seu poder de denúncia, reduzindo-a a um mero instrumento legitimador do status quo.

Ocorreu, assim, uma "falsa democratização" dos bens culturais, o que propiciou uma "falsa reconciliação" entre civilização e cultura, pois no momento em que a cultura se integra à lógica do mercado, deixa de ser cultura e torna-se valor de troca, já que os bens culturais passam a ser fabricados segundo os ditames do mercado e não mais tendo como parâmetro as aspirações ou desejos dos artistas; pois, segundo afirmam Adorno e Horkheimer (1985):

Os grandes artistas jamais foram aqueles que encarnaram o estilo da maneira mais íntegra e mais perfeita, mas aqueles que acolheram o estilo em sua obra como uma atitude dura contra a expressão caótica do sofrimento, como verdade negativa (p. 107).

Segundo Freitag (2004), essa "falsa reconciliação entre produção material e ideal de bens recebe o nome de 'indústria cultural'" ( $p$. 71). Portanto, o termo Indústria cultural é proposto por Adorno e Horkheimer em 1947, por ocasião da publicação da obra A Dialética 
do Esclarecimento, para contrapor termos ambíguos tais como "cultura de massa", "cultura popular" ou "arte popular" e esclarecer que se trata de dois fenômenos distintos:

\begin{abstract}
Abandonamos essa última expressão [cultura de massa] para substituí-la por "indústria cultural", a fim de excluir de antemão a interpretação que agrada aos advogados da coisa; estes pretendem, com efeito, que se trata de algo como uma cultura surgindo espontaneamente das próprias massas, em suma, da forma contemporânea da arte popular. Ora, dessa parte a indústria cultural se distingue radicalmente. Ao juntar elementos de há muito correntes, ela atribui-Ihes uma nova qualidade. Em todos os seus ramos fazem-se, mais ou menos segundo um plano, produtos adaptados ao consumo das massas e que em grande medida determinam esse consumo (ADORNO, 1978, p. 92).
\end{abstract}

Diante dessa afirmação de Adorno (1978), é possível perceber sua clareza em afirmar que "indústria cultural" e "cultura de massa" são dois fenômenos radicalmente distintos. O termo cultura de massa remete à ideia de que a cultura popular, por exemplo, arte, música, pintura são produzidas pela massa, ou seja, que é produto das vontades, inspirações ou ações do povo. Adorno e Horkheimer, no entanto, compreenderam que essa massa não era o "sujeito" desse processo, mas que em realidade existia uma indústria oculta que fabricava, mediante a união forçada entre a arte superior e a inferior, uma cultura para o consumo da massa; tendo sua orientação direcionada "segundo o princípio de sua comercialização e não segundo seu próprio conteúdo e sua figuração adequada" (ADORNO, 1978 , p. 93). Sendo assim, ele passa a defini-la como "a integração deliberada, a partir do alto, de seus consumidores" (ADORNO, 1978, p. 92), ou seja, não uma cultura que se origina nas massas, mas algo produzido a partir de uma racionalidade industrial para as massas.

Portanto, negando ambos os termos da expressão, ou seja, nem "cultura" nem "massa", eles denunciaram a impossibilidade de haver qualquer vestígio de igualdade entre "cultura de massa" e democratização da cultura ao sublinhar o caráter compulsório da indústria cultural. Nela é suprimida tanto a complexidade da cultura erudita quanto a rudeza espontânea da cultura popular que permitia resistir ao controle da "sociedade administrada". Sua finalidade não seria a de servir às massas, mas à racionalidade tecnológica e administrativa do grande capital produzindo, assim, uma falsa conciliação entre indivíduo e sociedade, sujeito e objeto, na qual o particular (indivíduo) seria diluído na universalidade do social, instaurando, desta forma, o reino da positividade e o culto ao presente imediato como a única forma de realidade possível. 
A ênfase no caráter integrador e conformista da indústria cultural é expressa no que Adorno (1978) considera de seu "imperativo categórico", qual seja: "tu deves submeter-te" (p. 97); uma submissão sem qualquer questionamento ao status quo, em troca de uma satisfação ilusória, porém "confortável", de que "o mundo está em ordem" (p. 99).

Neste sentido, Freitag (2004) lembra que a indústria cultural não é simplesmente mais um ramo da produção capitalista; em verdade ela foi concebida e organizada para preencher funções sociais específicas, antes satisfeitas pela cisão burguesa entre cultura e civilização. A nova produção cultural tem por função ocupar os antigos espaços de lazer dos trabalhadores, a fim de que estes não tenham oportunidade de refletir acerca da realidade à qual são submetidos; já que o objetivo da indústria cultural é transformar "a diversão em ausência de esforço de reflexão do consumidor" (GATTI, 2008, p. 31). Desta forma, suas intenções seriam a de assegurar a reprodução das relações sociais às quais os trabalhadores eram submetidos desde 0 início da revolução industrial. Segundo Adorno e Horkheimer (1985), a máquina capitalista girou para permanecer sempre a mesma, pois dentro dessa lógica "nada deve ficar como era, tudo deve estar em constante movimento. Pois só a vitória universal do ritmo da produção e reprodução mecânica é a garantia de que nada mudará, de que nada surgirá que não se adapte" (p. 111).

Faz-se importante, porém, destacar que não se trata de afirmar que - sujeito desse processo seriam os controladores da indústria cultural, pois como Cohn (1998) afirma, trata-se de um processo sem sujeito e a "questão fundamental é a do modo de produção daquilo de que se trata. No caso, aquilo que alude o termo 'indústria', ou seja, o capitalismo" (p. 19). Assim, torna-se claro que a intenção de Adorno e Horkheimer não era a de buscar vítimas ou algozes, mas sim denunciar o engodo a que são submetidas as massas "ao serem postas ideologicamente como sujeitos de um processo que precisamente só se sustenta como tal porque elas não têm como contestá-lo [...]" (COHN, 1998, p. 19), ou seja, um processo que se ampara mediante indivíduos que não possuem "esclarecimento" e/ou "autonomia" para contestá-lo, indivíduos presos à lógica capitalista na qual a razão prescinde de seus objetivos de emancipação humana para submeter-se aos princípios da comercialização de produtos.

A individuação assim forjada seria "pseudo-individuação", na medida em que não visaria à diferenciação entre indivíduo e sociedade, mas sim à mimese, à homogeneização das consciências. Nos termos de Adorno (1986), se trata

[...] do envolvimento da produção cultural de massa com a auréola da livre-escolha ou do mercado aberto, na base da própria estandardização, [a qual] [...] mantém os homens 
enquadrados, fazendo-os esquecer que o que eles escutam já é sempre escutado por eles, "pré-digerido" (p. 123).

Nesse sentido, pode-se compreender que o termo indústria cultural surgiu como uma forma de denúncia sobre as novas formas de dominação no capitalismo tardio, as quais não mais se restringiam ao mundo do trabalho, tendo se alastrado também para a esfera cultural; como Adorno (1978) afirma: "O consumidor não é rei, como a indústria cultural gostaria de fazer crer, ele não é sujeito dessa indústria, mas seu objeto" (p. 93). Assim, a denúncia dos autores da indústria cultural gira em torno do fato de que aquilo que "aparece como cultura circula como mercadoria" (COHN, 1998, p. 17).

Essas colocações sobre da Indústria cultural nos levam a refletir acerca da lógica capitalista contemporânea e seus sutis mecanismos de controle que, diversas vezes, apresentam-se tão habilmente disfarçados que não percebermos sua presença e muito menos sua eficácia. As reflexões adorno-horkheimianas nos direcionam para a compreensão de que não podemos considerar a realidade dada como "evidente", "natural", "desvelada"; mas que devemos suspeitar e buscar aquilo que está "camuflado", o "não-óbvio", para que possamos refletir dialeticamente acerca dos múltiplos fatores envolvidos em determinado fenômeno, a exemplo do objeto de estudo em destaque no presente artigo: a relação entre paixão, carro e brasileiros.

\section{Os dois gritos: do I piranga à I piranga}

O tema do presente artigo emergiu a partir de dois gritos que ecoam frequentemente no cenário brasileiro. O primeiro é proveniente do hino nacional brasileiro, o grito do I piranga: Ouviram do I piranga as margens plácidas de um povo heróico o brado retumbante...; um grito que nos remete ao momento de uma suposta conquista de liberdade do povo brasileiro ante a colonização portuguesa. Portanto, seria simbolicamente, mesmo que questionável em sua efetividade histórica, uma representação de liberdade, que tende a evocar no povo brasileiro, sentimentos de liberação.

Já o segundo grito ecoa da empresa petrolífera brasileira "Ipiranga". Aqui, o grito da I piranga, cujo slogan é: Apaixonados por carro como todo brasileiro, nos leva a refletir e questionar acerca de onde está a liberdade brasileira perante uma indústria cultural que busca moldar identidades ao afirmar categoricamente que todos os brasileiros são apaixonados por carro.

O mercado de publicitário utiliza variadas estratégias de divulgação, seja pela televisão, nos jornais, no rádio, na web ou em outdoors. Dentre estes múltiplos meios de comunicação, escolhemos como base 
de busca de informações e percepções das pessoas acerca da "paixão de todos os brasileiros" por carros, a internet. Ao todo, foram coletados depoimentos e reflexões em doze sites. Para a obtenção dos dados, foi utilizado o slogan publicitário da Ipiranga: "Apaixonados por carro como todo brasileiro" na área de busca do site de pesquisas Google.

Encontramos diversos endereços eletrônicos relacionados ao slogan da Ipiranga, nos quais foram coletadas declarações e opiniões diversificadas. Alguns sites funcionam como locais de troca de informações sobre o automobilismo, nos quais se discutem acerca dos mais variados tipos de carros, as origens das marcas, os combustíveis utilizados, etc. Nestes espaços, os internautas também conversam sobre o "fascínio" que os veículos automotores exercem em alguns deles. É interessante salientar que este "fascínio", muitas vezes, parece ser gerado na infância mediante o consumo de réplicas miniaturizada de automóveis, como exemplifica 0 seguinte depoimento:

\begin{abstract}
Alguns homens são fascinados por essas máquinas, a verdade é que desde sua infância, eles convivem com carros, mesmo que estes sejam de brinquedos. Geralmente é o presente mais esperado em aniversários. Os meninos ficam enlouquecidos com tantos modelos, cores e diferentes funções que o mercado oferece. Portanto, eles crescem já com esta visão e quando chegam à idade adulta, é lógico que desejam possuir um de verdade (APAIXONADO, 2005a).
\end{abstract}

Em outros momentos, encontramos declarações de pessoas que parecem transferir para os carros sentimentos de estima e de cuidado que geralmente dirigimos para entes queridos:

O brasileiro trata um carro quase como uma pessoa. Ele conversa com ele, dá banho, ele cuida, zela (APAIXONADO, 2005a).

Outros depoimentos demonstram que a "afeição" pelos automóveis acaba por promover o consumo de produtos relacionados ao tema automobilístico:

Eu sou aficionado por carros, como todo brasileiro (lembra daquele comercial da Ipiranga?) e sempre colecionei a revista 4 Rodas, pelo menos enquanto estive no Brasil (APAIXONADO, 2009b).

$\mathrm{Na}$ afirmação acima, percebemos a utilização, pelo internauta, do slogan da campanha de marketing da Ipiranga, o que demonstra a repercussão desta na constituição da opinião popular acerca da paixão brasileira por carros. Em outros sites, coletamos novas 
declarações que também empregam o referido slogan, o que reafirma a influência midiática na formação dos julgamentos do homem brasileiro acerca deste tema:

É pura verdade. Todo brasileiro tem uma "paixão por carros" (APAIXONADO, 2009a).

Seguindo a lógica: sou brasileira: amo carros (APAIXONADO, 2005b).

A quebra desta "lógica", que pode ocorrer devido à situação financeira precária de algumas pessoas, é prontamente resolvida mediante "soluções" oferecidas tanto pelas montadoras (financiamentos), quanto pelo governo (redução de impostos); o que acaba por gerar um aumento nas vendas dos veículos; como exemplificam as seguintes declarações:

O último fim de semana de IPI zero movimenta revendas (APAIXONADO, 2009c).

Com a venda de veículos leves aquecida, 1,914 milhão de carros novos - entre nacionais e importados - entraram para a frota brasileira de janeiro a agosto deste ano. Conforme a Associação Nacional dos Fabricantes de Veículos Automotores, isso significa um aumento de 3,9\% em relação ao mesmo período do ano passado, quando foram comercializados 1,842 milhão de unidades (APAIXONADO, 2009c).

De acordo com o exposto, percebemos que as empresas e o Governo parecem derramar-se em benesses ao consumidor, ou seja, fazem tudo que lhes é possível, em termos mercadológicos, para que nenhum dos brasileiros fique sem a sua "paixão". No entanto, alguns navegantes da web afirmam que, mesmo com estas "facilidades", o "sonho" de possuir um carro mostra-se "intangível", o que é compreensível diante da realidade financeira desfavorável para grande parcela da população brasileira. Entretanto, é curioso observar a declaração de que, mesmo que precise pagar "muito caro", a pessoa que for realmente "louca por carros", fará de tudo para "conquistar essa paixão":

Esse sonho de consumo para a maioria dos brasileiros é inatingível, infelizmente não há condições para a população em geral, os juros são altos, a economia não sabe que rumo tomar e assim por diante. Entretanto, quem realmente é louco por carros, não olha pra esses detalhes, compra e pronto, nem que seja um popular, mesmo que pague muito caro, ele vai conquistar esta paixão (APAIXONADO, 2005a). 
Encontramo-nos, assim, imersos em uma sociedade de consumo, cujos produtos vem atender a supostos desejos naturais dos homens ("quem é louco por carros"), ofertando produtos naturalmente almejados por todos os brasileiros, pagos a qualquer preço, sem valer-se de uma racionalidade econômica ("...não olha para esses detalhes, compra e pronto"), mas pautados em sua "loucura".

Esta naturalização dos fatos nos remete ao que Severiano e Estramiana (2006) afirmam acerca da propagação dos fenômenos como sendo "verdades naturais", cujo objetivo é manter as relações sociais não problematizáveis, reconciliando, desta forma, indivíduo e sociedade em uma totalidade homogeneizadora; com sérios prejuízos para o pensamento crítico reflexivo e para a perpetuação da unidimensionalização ${ }^{7}$ da vida humana.

Os referidos autores colocam que cada época histórica desenvolve várias "imagens dos homens", originadas a partir de um determinado contexto socioeconômico e cultural. Assim, percebemos que por trás das supostas essências, das aclamadas "verdades absolutas", ou das "loucuras" e/ou "paixões" tão aclamadas como "verdades intrínsecas" ao homem, existe uma indústria que cria, divulga e propaga imagens, tendências e "estilos de vida" que terminam por gerar as posições comportamentais que melhor se afinem com os propósitos mercantis vigentes. Por isso, é necessário ficar atento ao intrincado jogo de poderes, buscando analisar os fenômenos tendo por base uma teoria crítica, pois, como já nos alertaram Adorno e Horkheimer (1985): "tudo se passa como se uma instância onipresente houvesse examinado o material e estabelecido o catálogo oficial dos bens culturais, registrando de maneira clara e concisa as séries disponíveis" (p. 111); ou seja, ditando e naturalizando uma realidade que, em verdade, foi socialmente construída.

Outro ponto a salientar é o dado de que após o lançamento da referida campanha de marketing da Ipiranga, o número de brasileiros apaixonados por carro aumentou, como afirma este publicitário:

O estudo apontou que o grupo de apaixonados por carro cresceu tanto desde que este conceito foi lançado que já existe um "mundo" de pessoas apaixonadas por carros (APAIXONADO, 2009d).

Esta campanha atingiu resultados tão profícuos que formou as diretrizes para a próxima peça publicitária, cujo slogan é: "Para apaixonados por carro, tudo". Segundo o referido site,

(...) a ideia é envolver os consumidores através do conceito de comunidade, para que eles reforcem o entendimento de que pertencem a um grupo exclusivo que conta com 
inúmeras vantagens oferecidas pela Ipiranga (APAIXONADO, 2009d).

Assim, a "nova" campanha buscará "encantar" os consumidores através das diretrizes já utilizadas, pois, como colocado acima, seria uma garantia de sucesso nas vendas. Adorno e Horkheimer (1985) têm algo a dizer sobre isso, pois para eles "a máquina gira sem sair do lugar. Ao mesmo tempo em que já determina o consumo, ela descarta o que ainda não foi experimentado porque é um risco" ( $p$. $111)$; ou seja, a indústria cultural sempre se utiliza das mesmas estratégias travestidas de novas roupagens, visto estas serem a garantia de que a sociedade continuará a ser exatamente como é: racionalmente administrada. Desta forma, salientamos que os consumidores têm "liberdade" de "escolher o que sempre é a mesma coisa" (ADORNO; HOKHEIMER, 1985, p. 138).

Entre as declarações coletadas, observamos também comentários de homens que esperam, de forma "encantada", os lançamentos dos carros, pois adquirir o novo modelo representa o "reconhecimento" e a "auto-realização" perante os colegas ${ }^{8}$. Também foi possível perceber que alguns internautas parecem viver o ato da compra de um carro como se fosse um momento presente desvinculado de experiências passadas (a caducidade dos velhos modelos) e eternizado no "agora" sem futuro (virão novos modelos), como pode ser exemplificado através da seguinte declaração:

[os brasileiros que são apaixonados por carro] deixam de comprar um casa para comprar um carro, deixam ate de comer pra ter tal carro (...) deve, mas anda de carro (APAIXONADO, 2009a).

Esses processos regressivos engendrados pelo consumo fetichizado envolvem uma renúncia do enfrentamento da realidade, um esvaziamento dos vínculos alteritários, com redução dos processos de reflexão crítica e uma exacerbação do fascínio por um objeto-engodo, que promete preencher as mais diversas "faltas" humanas, encerrando o sujeito em um pseudo-estado aconflitivo, camuflando ainda mais seus sentimentos de impotência e desamparo frente à realidade.

Desta maneira, questionamos que formas de subjetividade estão sendo constituídas atualmente, haja vista que, cada vez mais, os indivíduos buscam um sentido para sua individuação a partir dos "códigos de consumo" (SEVERIANO, 2007, p. 72). Neste sentido, concordamos com a atualização do termo adorniano "pseudoindividuação", passando este a significar na contemporaneidade: 
- processo que implica uma suposta diferenciação do indivíduo tendo por base a "eleição", pretensamente "livre", de estilos de consumo, já previamente estandardizados e articulados pela lógica do mercado, o qual se serve, fundamentalmente, da lógica do desejo para promover uma identificação idealizada com seus objetos (SEVERIANO, 2010, p.25).

Por fim, refletimos, a partir das colocações de Mezan (2002), que a referida campanha de marketing consegui atingir os fins mercadológicos ao qual se propôs, utilizando-se, para isso, de mecanismos que empregam claramente aspectos da subjetividade humana. O referido autor coloca que a Publicidade opera em dois níveis: 1) Conteúdo manifesto, que é focado nas características objetivas dos produtos e 2) Significados latentes, os reais responsáveis pela motivação da compra, que conseguem evocar os mais variados desejos humanos: possuir o objeto sexual, vencer 0 oponente, aplacar angústias, sentir-se seguro, realizar transgressões sociais, etc.

Observa-se, desta forma, a supremacia, sem precedentes, da esfera econômica travestida de "cultura" e "liberdade", a qual pode ser observada através da expansão do domínio do mercado para todas as esferas, expressa, por exemplo, na mecanização do tempo do ócio, transformando-o na própria extensão do trabalho; na criação das sempre "novas paixões" do consumidor e adaptação de seus produtos conforme fins apriorísticos da indústria e nas promessas sempre incumpridas de "felicidade", associadas aos produtos.

\section{Considerações (in) conclusas}

De acordo com Crochík (1998) cabe ao "projeto da cultura" a responsabilidade em propiciar um ambiente favorável ao desenvolvimento de um indivíduo emancipado e autônomo, ou seja, "dono de seu destino" (CROCHIK, 1998). Para tanto, este projeto deve ter duas funções. A primeira consiste em defender os homens das ameaças da natureza; já a segunda está relacionada à defesa do homem, enquanto também parte integrante da natureza, de "si mesmo e do outro". Neste sentido, "a cultura como realização da natureza humana define-se pelo enfrentamento do que ameaça o homem, presente tanto nos desafios da natureza quanto nas regras de relacionamento humano criadas por ela" (CROCHIK, 1998).

Desta forma, a cultura seria o meio através do qual seria possível a saída do homem do estado de indiferenciação em relação ao mundo, no qual se encontra em seu nascimento, em direção à individuação. A subjetividade definir-se-ia, assim, como um "terreno interno que se 
opõe ao mundo externo", mas que, no entanto, "só pode surgir deste" (CROCHIK, 1998).

Para Adorno o processo de individuação humana somente ocorre quando a pessoa se reconhece enquanto um indivíduo autônomo diferenciado dos outros homens e da natureza. Neste sentido, a característica distintiva da individualidade seria, exatamente, a percepção crítica da tensão homem-mundo externo (SEVERIANO, 2007, p. 110).

A partir destas considerações, acreditamos que atualmente não podemos falar que a cultura veiculada pela Indústria Cultural esteja cumprindo adequadamente seu papel, na medida em que não propicia o desenvolvimento de uma "individualidade" autônoma. Ao invés, fomenta as demandas de um mercado que, insidiosamente, proclama quais devem ser as "paixões", os sentimentos, modos de ser, pensar, agir e sonhar dos seus membros.

Finalizamos este artigo afirmando, portanto, que a "paixão" por carros dos brasileiros, veiculada pelo referido slogan publicitário, deve ser considerada uma fabricação do sistema, sendo, desta forma, um produto da indústria cultural e não uma "verdade natural" que surgiria espontaneamente da população enquanto uma cultura originária das massas.

Enquanto um dado particular, a referida campanha publicitária nos fornece dados para uma reflexão crítica acerca desta sociedade de consumo enquanto uma totalidade, corroborando as reflexões adorno-horkheimianas sobre a necessidade de despir a aparência de "cultura" dos atuais produtos de consumo, revelando a objetividade de suas funções mercantis.

Observamos que as críticas frankfurteanas continuam a reverberar no cenário brasileiro contemporâneo, no qual a indústria cultural ainda opera com eficácia, visto a naturalidade com que a afirmação de que "todo brasileiro é apaixonado por carros" se mostrou pouco questionada pela amostra de brasileiros por nós consultada.

Entretanto, não podemos, em absoluto, concluir que esta indústria se faça hegemônica, açambarcando a subjetividade de todos os brasileiros. Isto porque, apesar de minoritárias, também detectamos vozes de brasileiros que discordam desta proposição, refletindo acerca da veracidade desta "paixão". Eles não são apaixonados por carros, o que nos leva a considerar que subsistem formas de resistência e de tensão - ferramentas fundamentais aos processos de individualização:

Claro, a Globo tenta te convencer que tem tudo a ver com você. A Ipiranga, de que é apaixonado por carros. A Sadia, que você adora pipocas de frango. Mas, será que é assim mesmo? (APAIXONADO, 2007). 
Sou brasileiro e não sou "apaixonado por carro", adepto da bicicleta como seu principal meio de transporte na cidade de São Paulo desde 2006, o analista de sistemas tem um automóvel na garagem, mas só o utiliza em último caso (APAIXONADO, 2009e).

Em outro site ${ }^{9}$, nos deparamos com uma enquete cujo intuito era discutir acerca da seguinte frase: "Sou brasileiro e não sou apaixonado por carro". Nela, foram trocados 45 (quarenta e cinco) comentários pessoais a respeito do tema. Dentre estes, 35 (trinta e cinco) concordaram com a referida frase, ou seja, não são apaixonadas por carro como todo brasileiro.

Assim, nosso estudo aponta que "a paixão natural por carro" veiculada pela internet deve ser considerada um mecanismo da atual "indústria cultural" promovida por fábricas e revendedoras de automóveis e não oriundo de uma "cultura de massa" do povo brasileiro.

Esta "paixão", como muitas outras proclamadas pela indústria cultural, não emergiu espontaneamente dos brasileiros, mas, em verdade, foi construída para os brasileiros. Ela foi resultado de uma campanha publicitária que juntou três elementos que não necessariamente possuíam relação entre si - paixão, carro, brasileiros -, atribuiu a estes uma unidade "natural", conseguindo, assim, criar um novo nicho de mercado.

Mas o fetiche, ao final se evidencia, assim como a crítica frankfurteana evidencia sua atualidade ao revelar no slogan analisado, a marca indelével da indústria cultural: Ontem como hoje, nela "[...] para todos algo está previsto; para que ninguém escape, as distinções são acentuadas e difundidas" (ADORNO; HORKHEIMER, 1985 , p. 101).

\section{Referências}

ADORNO, T. A indústria cultural. In: COHN, G. (Org.). Comunicação e indústria cultural. 4. ed. São Paulo: Nacional, 1978.

Sobre música popular. In: COHN, G. (Org.). Theodor Adorno: Sociologia. São Paulo: Ática, 1986.

ADORNO, T.; HORKHEIMER, M. Dialética do esclarecimento. Rio de Janeiro: Zahar, 1985.

. Conceito de I luminismo. São Paulo: Nova Cultural, 2000.

APAIXONADO por carro. 2005a. Disponível em: <http://carros.viaki.com/apaixonado_por_carro.html>. Acesso em: 29 set 2009. 
APAIXONADO por carro. 2005b. Disponível em: <http://carrosimportados.blogspot.com/2005/07/apaixonada-porcarro-como-todo.html >. Acesso em: 29 set 2009.

APAIXONADO por carro. 2007. Disponível em: <http://www.overmundo.com.br/overblog/apaixonados-por-carros>. Acesso em: 29 set 2009.

APAIXONADO por carro. 2009a. Disponível em: <http://br.answers.yahoo.com/question/index?qid=20090820091209AAefY hT $>$. Acesso em: 29 set 2009.

APAIXONADO por carro. 2009b. Disponível em: <http://vidalnetto.blogmoleza.com/Lingua-solta-b1/Brasileiro-eapaixonado-por-carros-b1-p180.htm >. Acesso em: 29 set 2009.

APAIXONADO por carro. 2009c. Disponível em: <http://br.invertia.com/noticias/noticia.aspx?idNoticia=200909261358_RE D_78422709>. Acesso em: 29 set 2009.

APAIXONADO por carro. 2009d. Disponível em: <http://www.propmark.com.br/publique/cgi/cgilua.exe/sys/start.htm?infoid $=51498 \&$ sid $=3 \&$ tpl=printerview $>$. Acesso em: 29 set 2009 .

APAIXONADO por carro. 2009e. Disponível em: <http://g1.globo.com/Sites/Especiais/Noticias/0,,MUL1273759-17396,00SOU+BRASILEIRO+E+NAO+SOU+APAIXONADO+POR+CARRO+DIZ+ADEPT O+DA+BICICLETA.html>. Acesso em: 29 set 2009.

ARAÚJO, J. C. (Org.). Internet \& ensino: novos Gêneros, outros desafios. Rio de Janeiro: Lucerna, 2007.

BAUDRILLARD, J. A sociedade de consumo. Lisboa: Edições 70, 1970.

BUZATO, M. Inclusão digital como invenção do quotidiano: um estudo de caso. Revista Brasileira de Educação, v. 13, n. 38, p. 325-342, maio/ago, 2008.

CHAUÍ, M. Convite à Filosofia. São Paulo: Ática S.A., 1995.

COHN, G. A atualidade do conceito de indústria cultural. In: MOREIRA, A. (Org.). Sociedade global: cultura e religião. São Paulo: Vozes, 1998.

CROCHÍK, J. L. Os desafios atuais do estudo da subjetividade na Psicologia. Psicologia USP, São Paulo, v. 9, n. 2, p. 69-85, 1998.

EWALD, A. P.; SOARES, J. C. Identidade e subjetividade numa era de incerteza. Estudos de Psicologia, Natal, v. 12, p. 23-30, 2007.

FREITAG, B. A teoria crítica ontem e hoje. São Paulo: Editora Brasiliense, 2004.

GATTI, L. T. W. Adorno e a indústria cultural. In: Revista Mente, Cérebro \& Filosofia - O homem no caos do capitalismo moderno: Adorno, Horkneimer, Fromm, Benjamin. São Paulo: Ediouro, v. 07, 2008, p. 25-33.

HEGEL, G. Fenomenologia do espírito. São Paulo: Nova Cultural Ltda, 2000. 
KANT, I. Crítica da razão pura. São Paulo: Nova Cultural Ltda, 2000. (Coleção Os Pensadores).

LEVY, P. A inteligência coletiva: por uma Antropologia do ciberespaço. São Paulo: Loyola, 2000.

MATOS, O. A escola de Frankfurt: luzes e sombras do iluminismo. São Paulo: Editora Moderna, 2005.

MARX, K. Fetichismo e reificação. In: IANNI, O. Sociologia. São Paulo, Ática, 1984.

MEZAN, R. Interfaces da Psicanálise. São Paulo: Companhia das letras, 2002.

OLIVEIRA. M. Ética e racionalidade moderna. São Paulo: Loyola, 1993.

RAMOS, C. A dominação do corpo no mundo administrado. São Paulo: Escuta, 2004.

ROUANET, S. Teoria crítica e psicanálise. Rio de Janeiro: Tempo brasileiro, 1983.

As razões do Iluminismo. São Paulo: Companhia das Letras, 1987.

SEVERIANO, M. F. e ALVARO, J. L. Consumo, narcisismo e identidades contemporâneas: uma análise psicossocial. Rio de Janeiro: EdUERJ, 2006.

SEVERIANO, M. F. Narcisismo publicidade: uma análise psicossocial dos ideais de consumo na contemporaneidade. São Paulo: Annablume, 2007.

SEVERIANO, M. F. V. "Lógica do mercado" e "lógica do desejo": reflexões críticas sobre a sociedade de consumo contemporânea a partir da Escola de Frankfurt. In: SOARES, J. C. S. (Org.). Escola de Frankfurt: inquietudes da razão e da emoção. 1 ed. Rio de Janeiro: EdUERJ, 2010, p. 121-141.

SOARES, J. Escola de Frankfurt: unindo materialismo e psicanálise na construção de uma psicologia social marginal. In: JACÓ-VILELA, A.; FERREIRA, A.; PORTUGAL, F. (Orgs.). História da Psicologia: rumos e percursos. Rio de Janeiro: Nau Editora, 2007. p. 473-501

\section{Endereço para correspondência}

\section{Rebeca Carvalho de Morais}

Av. Muriatiapua, 200, Cs 66, Lagoa Redonda, CEP 60831-301, Fortaleza, Ceará, Brasil

Endereço eletrônico: rebecademorais@hotmail.com

Jesus Garcia Pascual

R. Ildefonso Albano, 2021, apt. 301, Meireles, CEP 60.115-000, Fortaleza, Ceará, Brasil

Endereço eletrônico: garciapascual2001@yahoo.com.br

Maria de Fátima Vieira Severiano

Av. Rui Barbosa, n.604, apto. 401, Meireles, CEP 60.115-220, Fortaleza - CE, Brasil Endereço eletrônico: fatimasev@terra.com.br 
Recebido em: 23/02/2010

Reformulado em: 26/08/2010

Aceito para publicação em: 27/09/2010

Acompanhamento do processo editorial: Rita Maria Manso de Barros

\section{Notas}

* Mestre em Psicologia.

**Doutor em Educação Brasileira.

***Doutora em Ciências Sociais Aplicadas à Educação pela UNICAMP e pelo Depto. De Psicologia Social da Universidad Complutense de Madrid;

${ }^{1} O$ slogan desta campanha pode ser encontrado no site da empresa Ipiranga: $<$ www.ipiranga.com.br>.

${ }^{2}$ Segundo Rouanet (1983), alguns procedimentos de pesquisa baseiam-se num método que Adorno e Horkheimer denominaram de "transcendente". Esta prática não estaria interessada no "conteúdo" dos objetos, mas sim em sua "localização", ou seja, no lugar que estes ocupam dentro de um sistema classificatório; por isso Adorno afirma que este seria um pensamento "topológico", já que "situa o objeto, sem captar sua essência" (ROUANET, 1983, p. 103).

${ }^{3}$ Faz-se importante esclarecer que concordamos com Adorno e Horkheimer (1985) ao afirmarem que "tanto técnica quanto economicamente, a publicidade e a indústria cultural se confundem"(p. 135), por isso, por diversas vezes, mídia e indústria cultural serão utilizadas como sinônimos no decorrer deste artigo.

${ }^{4}$ Ver quadro de Referências de Sites

${ }^{5}$ Para um esclarecimento mais detalhado sobre esse ponto, ver SEVERIANO, M.F.V. Narcisismo e Publicidade: uma análise psicossocial dos ideais de consumo na contemporaneidade. São Paulo: Annablume, 2007.

${ }^{6}$ Para uma melhor compreensão do conceito de Racionalidade Instrumental, podemos mencionar a bomba atômica, que é um exemplo do grande refinamento científico que a humanidade alcançou, mas que possui em si a potência de destruir essa mesma humanidade.

${ }^{7} O$ conceito de unidimensionalização foi proposto por Marcuse para falar do estabelecimento de um mundo quase totalmente administrado: a sociedade unidimensional, que é "caracterizada pela abundância e por uma racionalidade dominadora, na qual o progresso tecnológico e científico, juntamente com os mais sofisticados meios de comunicação, passa a produzir e direcionar o homem em todas as suas dimensões, de forma imperceptível, fabricando seus desejos e necessidades, paralisando a consciência crítica e transformando a sociedade num mundo sem oposição" (SEVERIANO, 2007, p. 35).

${ }^{8}$ Apontamos aqui outra estratégia utilizada pelos media que consiste no fato da venda de um produto não ser focada exclusivamente no consumidor, mas, principalmente, na diferenciação que este conseguirá obter, com relação aos outros homens, ao consumir uma determinada mercadoria. Assim, ao comprar um objeto, o indivíduo não se tornará unicamente "melhor", mais "belo" ou mais "feliz"; mas sim "melhor", mais "belo", e mais "feliz" do que as outras pessoas. A relação com os demais é utilizada para que seja possível destacar o indivíduo, promovendo, assim, uma "diferenciação" e, consequentemente, uma "personalização" via consumo de objetos. É neste sentido que Baudrillard (1970) afirma que a Publicidade busca "atingir cada qual em função dos outros, nas suas veleidades de prestígio social reificado" (p. 64). 
Rebeca Carvalho de Morais, Jesus Garcia Pascual, Maria de Fátima Vieira Severiano

"Apaixonados por carros como todo brasileiro" (?)

${ }^{9}$ Esta enquete encontra-se disponível em:

<http://topsy.com/tb/g1.globo.com/Sites/Especiais/Noticias/0,,MUL1273759-

17396,00-> Acesso em: 30 set. 2009. 